\title{
A Unique Case of Renovascular Hypertension Caused by Combined Renal Artery Disease
}

\author{
Atsushi Morimoto, Akira Nakatani, Kazunori Matsui, Toshio Hashimoto, \\ Munehiro Maeda*, Hideo Uchida*, and Kazuhiro Dohi
}

\begin{abstract}
We present a unique case of renovascular hypertension due to combined renal artery disease in a 22year-old woman. Renal angiography revealed renal artery stenosis with poststenotic dilatation and an aneurysm due to fibromuscular dysplasia in the left kidney, and a congenital arteriovenous fistula in the right kidney. The results of a captopril test and plasma renin sampling demonstrated that the reninangiotensin-aldosterone system was stimulated in both kidneys, accounting for the hypertension in this patient. Almost all cases of renovascular hypertension are due to only one underlying renal artery disease. This is the first case of renovascular hypertension associated not only with renal artery stenosis and an aneurysm due to fibromuscular dysplasia, but also with a congenital arteriovenous fistula. (Hypertens Res 1995; 18: 255-257)
\end{abstract}

Key Words: congenital arteriovenous fistula, fibromuscular dysplasia, renovascular hypertension

Patients with renovascular hypertension represent less than $5 \%$ of all hypertensive patients; this secondary form of high blood pressure is the most common correctable cause of secondary hypertension (1). Almost all cases of renovascular hypertension are due to only one underlying renal artery disease, such as fibromuscular dysplasia or arteriosclerosis. Cases of renovascular hypertension with multiple underlying causes are rare. We report here a patient with renovascular hypertension induced by combined bilateral renal artery disease, consisting of unilateral renal artery stenosis with an associated renal artery aneurysm due to fibromuscular dysplasia, and a contralateral congenital arteriovenous fistula.

\section{Case Report}

A 22-year-old woman was admitted to the Nara Medical University Hospital in July of 1993 for further evaluation of hypertension that had been diagnosed 1 month earlier at blood donation by chance. At that time, her blood pressure was $170 / 120 \mathrm{mmHg}$. She went to a nearby hospital, and the blood pressure was found to be $200 / 110 \mathrm{mmHg}$ and the plasma renin activity $4.7 \mathrm{ng} / \mathrm{ml} / \mathrm{h}$. She was not obese and did not smoke. There was no past history of trauma or renal disease and no family history of hypertension.

On admission, her blood pressure while sitting at rest was $152 / 90 \mathrm{mmHg}$ and her heart rate was 74 beats per minute under administration of $30 \mathrm{mg}$ of nifedipine, $0.5 \mathrm{mg}$ of prazosin and $40 \mathrm{mg}$ of meto- prolol. No bruits were audible in the neck, chest or abdomen. Her optic fundi were classified as H1S0, Keith-Wagener I.

Blood chemistry and hematologic findings were unremarkable (Table 1). Examination of plasma renin activity and plasma aldosterone concentration was performed while resting at 07:00 in the morning, 7 days after terminating drug administration and receiving a diet containing $7 \mathrm{mg}$ of $\mathrm{NaCl} / \mathrm{d}$, revealed normal values.

The electrocardiogram was normal but mild left ventricular hypertrophy was noted in the echocardiogram. Chest radiography revealed normal cardiac size with a cardiothoracic ratio of $38 \%$. Left and right renal size were 10.4 and $9.4 \mathrm{~mm}$. Renography demonstrated no significant lateralization of renal function.

Captopril test was performed and the results were the following. At rest, the plasma renin activity was $1.60 \mathrm{ng} / \mathrm{ml} / \mathrm{h}$ and the blood pressure was $174 / 92$ $\mathrm{mmHg}$. One hour after the oral administration of $25 \mathrm{mg}$ of captopril, the plasma renin activity increased to $20.0 \mathrm{ng} / \mathrm{ml} / \mathrm{h}$ and the blood pressure decreased to $138 / 88 \mathrm{mmHg}$.

Angiography was performed in conjunction with selective sampling of plasma renin activity. Angiography revealed an arteriovenous fistula in the right, lower interlobular artery. The left kidney showed severe stenosis with poststenotic dilatation in the upper interlobular artery and an aneurysm in the lower interlobular artery (Fig. 1). Renal vein renin activities were elevated bilaterally, although renin activity in the lower inferior vena cava was nor-

From the First Department of Internal Medicine and * Department of Radiology, Nara Medical University.

Address for Reprints: Department of Internal Medicine, National Cardiovascular Center. 5-7-1, Fujishirodai, Suita 565, Japan.

Received September 20, 1994; accepted February 23, 1995. 


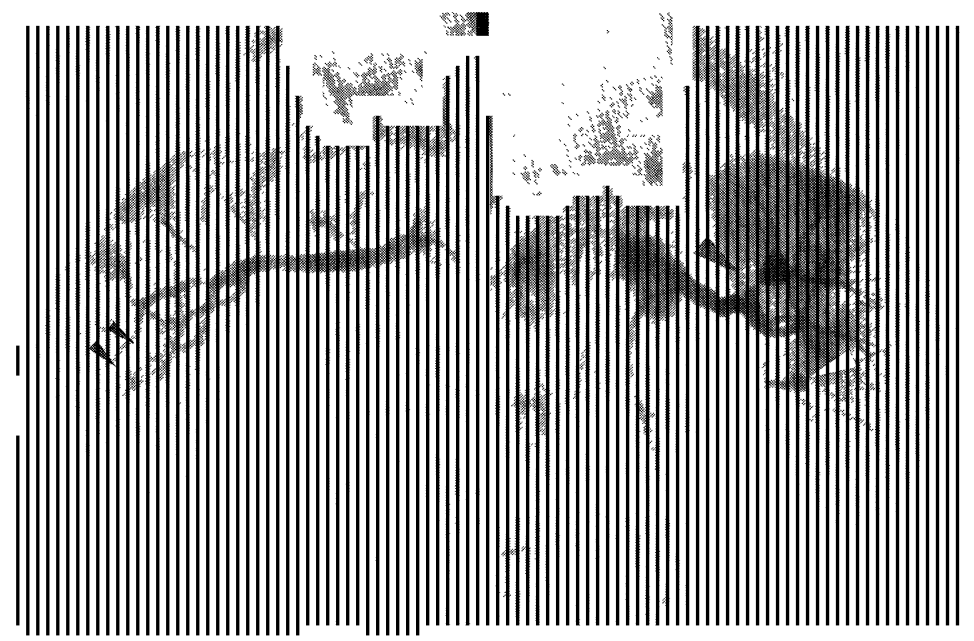

Fig. 1. Renal arteriogram. An arteriovenous fistula is demonstrated in the right kidney (arrows). Severe stenosis, with poststenotic dilatation (white arrow), and an aneurysm (black arrow) are demonstrated in the left kidney.

Table 1. Laboratory Data on Admission

\begin{tabular}{lrllr}
\hline & \multicolumn{4}{c}{ Blood chemistry } \\
\hline Urinalysis & & & & \\
Occult blood & $(-)$ & T.P. & 6.9 & $\mathrm{~g} / \mathrm{dl}$ \\
$\quad$ Protein & $(-)$ & Alb & 4.0 & $\mathrm{~g} / \mathrm{dl}$ \\
Hematology & & BUN & 11 & $\mathrm{mg} / \mathrm{dl}$ \\
RBC $390 \times 10^{4}$ & $/ \mu l$ & Cr & 0.5 & $\mathrm{mg} / \mathrm{dl}$ \\
Hb 12.3 & $\mathrm{~g} / \mathrm{dl}$ & T-Chol & 153 & $\mathrm{mg} / \mathrm{dl}$ \\
Ht 36.1 & $\%$ & TG & 59 & $\mathrm{mg} / \mathrm{dl}$ \\
WBC 3650 & $/ \mu l$ & FBS & 88 & $\mathrm{mg} / \mathrm{dl}$ \\
Plt $20.5 \times 10^{4}$ & $/ \mu l$ & Na & 140 & $\mathrm{mEq} / 1$ \\
& & $\mathrm{~K}$ & 3.9 & $\mathrm{mEq} / 1$ \\
& & $\mathrm{Cl}$ & $103 \mathrm{mEq} / 1$ \\
\hline
\end{tabular}

mal (Table 2). The right renal renin index was 0.76 , and the left renal renin index was 1.29 . The renal vein renin ratio was 1.30 .

After admission, her blood pressure was about 170-200/100-120 $\mathrm{mmHg}$ under no drug administration, but under the oral administration of $50 \mathrm{mg}$ of alacepril, her blood pressure was controlled to about $140-150 / 80-90 \mathrm{mmHg}$. Percutaneous or surgical renal angioplasty and embolization were considered in this patient but were not performed because she refused surgical treatment. Her blood pressure has been well controlled with the oral administration of $50 \mathrm{mg}$ of alacepril and $40 \mathrm{mg}$ of nifedipine.

\section{Discussion}

Renovascular hypertension is the most common form of secondary hypertension (1). Renal artery disease is due to atherosclerosis in approximately $60 \%$ of patients and to fibromuscular dysplasia, usually medial fibroplasia, in approximately $40 \%$ of patients. Less than $1 \%$ of cases are caused by non-
Table 2. Results of Plasma Renin Activity Sampling

\begin{tabular}{lcc}
\hline & $\begin{array}{c}\text { Renin } \\
(\mathrm{ng} / \mathrm{ml} / \mathrm{h})\end{array}$ & $\begin{array}{c}\text { Aldosterone } \\
(\mathrm{pg} / \mathrm{ml})\end{array}$ \\
\hline IVC, Upper & 5.57 & 59.1 \\
IVC, Lower & 3.20 & 60.1 \\
Left renal vein & 7.34 & 92.1 \\
Right renal vein & 5.63 & 75.6 \\
\hline
\end{tabular}

IVC, inferior vena cava.

stenotic renal artery diseases, such as arteriovenous fistulas, dissecting aortic aneurysms, renal artery aneurysms, renal infarctions, extrinsic vascular compression or trauma (2).

In Japan, greater than $85 \%$ of cases of renovascular hypertension result from renal artery stenosis. Cases of renovascular hypertension which result from nonstenotic artery disease are rare, and cases of combined renal artery disease are associated with this condition. In the patient reported here, the captopril test suggested that the elevation in blood pressure was due to activation of the reninangiotensin-aldosterone system (3). The results of angiography and renal vein renin activity sampling suggested that the cause of hypertension in our patient was secondary to exaggerated secretion of renin from both kidneys (4).

This evidence strongly suggests that abnormalities in each kidney contributed to the hypertension in this patient. The arteriovenous fistula caused an elevation in the renin secretion of the right kidney by shunting blood flow away from the renal parenchyma. The contralateral renal artery stenosis and aneurysm caused an increase in the renin secretion of the left kidney. We believe this exaggerated plasma renin activity caused the observed hypertension. The aneurysmal dilatation of segments of the renal artery in fibromuscular dysplasia results in degeneration of the elastic fibers and a local weakening of 
the arterial wall, leading to renal artery stenosis and aneurysms (5-7). The arteriovenous fistula in the right kidney may have been congenital, given the absence of angiographic features of fibromuscular dysplasia, ruptured aneurysms, or displacement of adjacent structures, as well as the absence of a history of trauma $(6,7)$.

Generally, severe renal artery stenosis causes hypertension by the production of a pressure gradient, which results in renal ischemia. Aneurysms cause hypertension by compressing renal vessels and producing perianeurysmal hypoperfusion. Arteriovenous fistulas cause hypertension by producing a short circuit of blood, resulting in local ischemia (7). In this case, all three of these pathogenic mechanisms played a role in the development of this patient's hypertension.

There are few case reports of renovascular hypertension featuring combined causes of hypertension $(8-10)$. This is the first report describing unilateral fibromuscular dysplasia complicated by renal artery stenosis and an aneurysm in conjunction with a contralateral congenital arteriovenous fistula; in this patient both lesions were functionally significant, resulting in increased renin secretion and hypertension.

\section{References}

1. Working group of renovascular hypertension: Detection, evaluation, and treatment of renovascular hypertension. Arch Intern Med 1987; 147: 820-829.

2. Oldenburg WA: Renovascular hypertension: Difficulties in diagnosis and treatment. Postgrad Med 1991; 89: 93-109.

3. Muller FB, Sealey JE, Case DB, et al: The captopril test for identifying renovascular hypertensive patients. Am J Med 1986; 80: 633-644.

4. Sealey JE: The physiology of renin secretion rate and renal plasma flow from peripheral and renal vein levels. Am J Med 1973; 55: 391-401.

5. Edgar G, Harrison JR, Lawrence J: Pathologic classification of renal arterial disease in renovascular hypertension. Mayo Clin Proc 1971; 46: 161-167.

6. Novick AC: Renovascular hypertension; Surgical treatment, in Laragh JH, Brenner BM (eds): Hypertension; Pathophysiology, Diagnosis, and Management. New York, Raven Press, 1990, pp1561-1571.

7. Stuckmann G, Antonucci F, Zollikofer C: Angiographical diagnosis of renovascular (and renal parenchymatous) hypertension, in Luscher TF, Kaplan NM (eds): Renovascular and Parenchymatous Hypertension. Berlin, Springer Verlag, 1992, pp150-178.

8. Wilfrido $\mathrm{CZ}$, Christoph Z, Oscar VD, et al: Giant aneurysms of the renal arteries: An unusual manifestation of fibromuscular dysplasia. Radiology 1979; 133: $327-330$.

9. Herbert AO, Sheldon GS, Philip EB, et al: An unusual cause of renal arteriovenous fistula-fibromuscular dysplasia of the renal arteries. Mayo Clin Proc 1973; 48: 207-210.

10. Bron KM, Redman H: Renal arteriovenous fistula and fibromuscular hyperplasia: a new association. Ann Intern Med 1968; 68: 1039-1043. 